\title{
Role of Cortisol in the Pathogenesis of Deficient Counterregulation after Antecedent Hypoglycemia in Normal Humans
}

\author{
Stephen Neil Davis, Chris Shavers, Fernando Costa, and Rogelio Mosqueda-Garcia \\ Department of Medicine, Vanderbilt University School of Medicine, Nashville, Tennessee 37232
}

\begin{abstract}
The aim of this study was to determine the role of increased plasma cortisol levels in the pathogenesis of hypoglycemiaassociated autonomic failure. Experiments were carried out on 16 lean, healthy, overnight fasted male subjects. One group $(n=8)$ underwent two separate, 2-d randomized experiments separated by at least 2 mo. On day 1 insulin was infused at a rate of $1.5 \mathrm{mU} / \mathrm{kg}$ per min and $2 \mathrm{~h}$ clamped hypoglycemia $(53 \pm 2 \mathrm{mg} / \mathrm{dl})$ or euglycemia $(93 \pm 3 \mathrm{mg} / \mathrm{dl})$ was obtained during morning and afternoon. The next morning subjects underwent a 2 -h hyperinsulinemic $(1.5 \mathrm{mU} / \mathrm{kg}$ per $\mathrm{min})$ hypoglycemic $(53 \pm 2 \mathrm{mg} / \mathrm{dl})$ clamp study. In the other group $(n=8)$, day 1 consisted of morning and afternoon 2-h clamped hyperinsulinemic euglycemia with cortisol infused to stimulate levels of plasma cortisol occurring during clamped hypoglycemia $(53 \mathrm{mg} / \mathrm{dl})$. The next morning (day 2) subjects underwent a 2-h hyperinsulinemic hypoglycemic clamp identical to the first group. Despite equivalent day 2 plasma glucose and insulin levels, steady state epinephrine, norepinephrine, pancreatic polypeptide, glucagon, ACTH and muscle sympathetic nerve activity (MSNA) values were significantly $(P<0.01)$ blunted after day 1 cortisol infusion compared to antecedent euglycemia. Compared to day 1 cortisol, antecedent hypoglycemia produced similar blunted day 2 responses of epinephrine, norepinephrine, pancreatic polypeptide and MSNA compared to day 1 cortisol. Antecedent hypoglycemia, however, produced a more pronounced blunting of plasma glucagon, $\mathrm{ACTH}$, and hepatic glucose production compared to day 1 cortisol. We conclude that in healthy overnight fasted men $(a)$ antecedent physiologic increases of plasma cortisol can significantly blunt epinephrine, norepinephrine, glucagon, and MSNA responses to subsequent hypoglycemia and $(b)$ these data suggest that increased plasma cortisol is the mechanism responsible for antecedent hypoglycemia causing hypoglycemia associated autonomic failure. (J. Clin. Invest. 1996. 98:680-691.) Key words: catecholamines $\cdot$ autonomic nervous system $\cdot$ hypoglycemia $\bullet$ cortisol $\cdot$ glucagon
\end{abstract}

Address correspondence to S.N. Davis, Diabetes Research and Training Center, Vanderbilt University School of Medicine, 715 Medical Research Building II, Nashville, TN 37232-6303. Phone: 615936-1653; FAX: 615-936-1667.

Received for publication 26 May 1995 and accepted in revised form 8 May 1996.

J. Clin. Invest.

(c) The American Society for Clinical Investigation, Inc.

0021-9738/96/08/0680/12 \$2.00

Volume 98, Number 3, August 1996, 680-691

\section{Introduction}

Intensively treated insulin-dependent patients (IDDM) $)^{1}$ frequently have syndromes of abnormal counterregulatory responses to hypoglycemia (1). These include deficient neuroendocrine hormonal responses, altered glycemia thresholds for counterregulatory hormone release, and hypoglycemia unawareness. It is thought that these syndromes of abnormal counterregulation contribute to the threefold greater incidence of severe hypoglycemia observed in intensively treated IDDM patients. Although intensively treated IDDM patients have reduced levels of all counterregulatory hormones in response to hypoglycemia, it is the deficient autonomic-adrenomedullary responses which result in serious clinical consequences. This occurs because long duration IDDM patients lose the ability to release glucagon in response to hypoglycemia (2) and become dependent upon epinephrine for effective hypoglycemic counterregulation (3). The exact mechanism responsible for deficient autonomic-adrenomedullary responses in intensively treated IDDM patients is not known. However, numerous recent studies have demonstrated that antecedent hypoglycemia can reduce some if not all aspects of the neuroendocrine and autonomic-adrenomedullary responses to subsequent hypoglycemia in normal (4-7) and IDDM patients (8-10). Furthermore, other studies have demonstrated that insulinoma patients have syndromes of abnormal hypoglycemic counterregulation similar to intensively treated IDDM patients which return to normal when the pancreatic tumor is removed (11-13). These data have therefore lead to the hypothesis that hypoglycemia-associated autonomic failure in IDDM patients is caused by antecedent iatrogenic hypoglycemia (1).

There is, however, no available information indicating mechanistically how hypoglycemia per se or a consequence of hypoglycemia may cause deficient autonomic-adrenomedullary counterregulatory responses. During the last decade there have been considerable advances in our understanding of the effects of glucocorticoids on neuroendocrine and autonomicadrenomedullary responses to stress. One important function of glucocorticoids is to protect the body against its own defense mechanisms which might cause damage if allowed to proceed unregulated. Conceptually, this idea can be related to a number of homeostatic mechanisms in addition to the classical role of glucocorticoids reducing an inflammatory response. Information exists from the 1950s reporting that glucocorticoids can reduce levels of catecholamines released in response to stress (14). More recent data have confirmed that glucocorticoids can reduce the autonomic-adrenomedullary responses

1. Abbreviations used in this paper: ACTH, adrenocorticotropin; ANS, autonomic nervous system; CV, coefficient of variation; HGP, hepatic glucose production; IDDM, insulin-dependent diabetes mellitus. 
to a variety of differing stress in humans and animals (15-18). Several studies have also demonstrated that glucocorticoid deficiency (induced by bilateral adrenalectomy) results in exaggerated autonomic responses to diverse stress such as cold exposure (19) or surgery (20). Other recent studies investigating the effects of raised levels of glucocorticoids on autonomicadrenomedullary function have been similarly consistent. Komesaroft and Funder (18) demonstrated that prior administration of dexamethasone could reduce the autonomic-adrenomedullary response to hypoglycemia in conscious sheep. Whereas Tappy et al. (21) reported that dexamethasone administration resulted in reductions of plasma norepinephrine levels during hyperinsulinemic-euglycemia in humans.

Taken together the above information indicates that glucocorticoids exert a restraining effect on autonomic-adrenomedullary function. Based upon these data, we have hypothesized that antecedent hypoglycemia causes reductions in autonomic-adrenomedullary responses to subsequent hypoglycemia due to elevations in plasma cortisol levels. The aim of the present study, therefore, was to determine in normal humans whether hypoglycemia associated autonomic failure is caused by antecedent increases in plasma cortisol.

\section{Methods}

\section{Subjects}

We studied 16 healthy male volunteers, $19-34$ years of age (25 $\pm 2 \mathrm{yr}$ ) with a mean body mass index of $23.2 \pm 0.6\left(\mathrm{~kg} / \mathrm{m}^{2}\right)$ and glycosylated hemoglobin $\left(\mathrm{HBA}_{1 \mathrm{C}}\right) 4.8 \pm 01 \%$ (normal range 4-6.5\%). None were taking medication nor had a family history of diabetes. Each subject had a normal blood count, plasma electrolytes, liver, and renal function.
All gave written informed consent. Studies were approved by the Vanderbilt University Human Subjects Institutional Review Board. The subjects were asked to follow their usual weight-maintaining diet for $3 \mathrm{~d}$ before each study. Each subject was admitted to the Vanderbilt Clinical Research Center (CRC) at 5:00 pm on the evening before an experiment. All subjects were studied after an overnight 10 -h fast.

\section{Experimental design}

Glucose clamp studies. Eight subjects attended for two separate 2-d experiments separated by at least 2 mo. The other eight subjects attended for a single 2-d experiment. The order of the three experiments were randomized and performed in a single blind fashion. On the morning of the first day of each study, after an overnight fast, two intravenous cannulae were inserted under $1 \%$ lidocaine local anesthesia. One cannula was placed in a retrograde fashion into a vein on the back of the hand. This hand was placed in a heated box (55$60^{\circ} \mathrm{C}$ ), so that arterialized blood could be obtained (22). The other cannula was placed in the contralateral arm so that $20 \%$ glucose could be infused via a variable-rate volumetric infusion pump (I med, San Diego, CA).

\section{Antecedent euglycemia experiments}

On the morning of day one (Fig. 1) after the insertion of venous cannulae a period of $90 \mathrm{~min}$ was allowed to elapse followed by a $30 \mathrm{~min}$ basal control period and a 120 min hyperinsulinemic-euglycemic experimental period. At time zero a primed continuous infusion of insulin (23) was administered at a rate of $1.5 \mathrm{mU} / \mathrm{kg}$ per min for $120 \mathrm{~min}$. Plasma glucose levels were measured every $5 \mathrm{~min}$ and a variable infusion of $20 \%$ dextrose was adjusted so that plasma glucose levels were held constant (24). KCL ( $20 \mathrm{mmol} / \mathrm{liter})$ was added to the glucose infusate in each study. After completion of the initial 2-h test period each subject received a small snack (15 grams of carbohydrate in the form of fruit juice) and their plasma glucose was maintained at euglycemia for a further $2 \mathrm{~h}$. At that point insulin was restarted and a sec-

\section{Experimental Protocol}

Antecedent Euglycemia

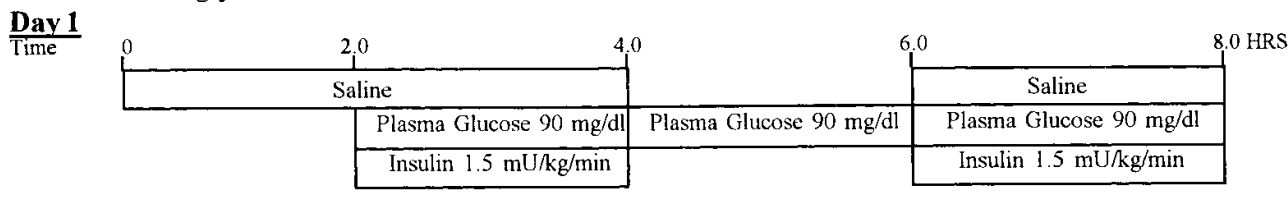

Antecedent Hypoglycemia

$$
<----- \text { Microneurography ----->> }
$$

Dav 1

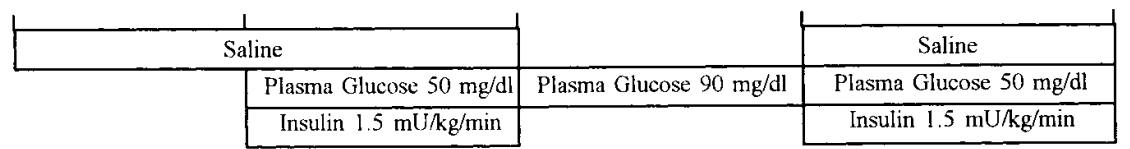

Antecedent Cortisol

|<-..-.- Microneurography -.....-> |

Day 1

\begin{tabular}{|c|c|c|}
\hline Saline & & Saline \\
\hline Plasma Glucose $90 \mathrm{mg} / \mathrm{dl}$ & Plasma Glucose $90 \mathrm{mg} / \mathrm{d}$ & Plasma Glucose $90 \mathrm{mg} / \mathrm{dl}$ \\
\hline Insulin $1.5 \mathrm{mU} / \mathrm{kg} / \mathrm{min}$ & & Insulin $1.5 \mathrm{mU} / \mathrm{kg} / \mathrm{min}$ \\
\hline Cortisol $2.0 \mu \mathrm{g} / \mathrm{kg} / \mathrm{min}$ & & Cortisol $2.0 \mu \mathrm{g} / \mathrm{kg} / \mathrm{min}$ \\
\hline
\end{tabular}

$\mid<---.--$ Microneurography -.---->|

Day 2 Common To All Protocols

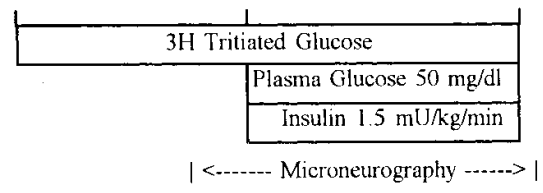

Each two day study was separated by two months and performed in a randomized fashion.
Figure 1. Schematic representation of experimental protocols used in this study. 
ond hyperinsulinemic-euglycemic clamp, identical to the morning, was performed. At completion of the second glucose clamp subjects consumed a large meal, bedtime snack, and remained in the Clinical Research Center.

\section{Antecedent hypoglycemia experiments}

These experiments followed a similar format to the previously described euglycemia experiments with the exception that on day 1 identical morning and afternoon hyperinsulinemic-hypoglycemic clamps of $53 \pm 2 \mathrm{mg} / \mathrm{dl}$ were performed. At completion of day 1 morning hypoglycemic experiments, subjects received a 15 gram carbohydrate snack and their plasma glucose was rapidly restored to normal by the use of an exogenous $20 \%$ glucose infusion. Plasma glucose was maintained at euglycemia for $2 \mathrm{~h}$ before afternoon hypoglycemic clamp experiments were performed.

\section{Antecedent cortisol during hyperinsulinemic-euglycemia experiments}

The experiments in this group involved a similar format to the previously described studies. On day 1 subjects underwent morning and afternoon hyperinsulinemic-euglycemic clamp experiments but with an additional constant infusion of cortisol $(2 \mu \mathrm{g} / \mathrm{kg}$ per min) to simulate the increase of plasma cortisol levels occurring during hypoglycemic experiments. In this protocol the effects of an isolated physiologic increase of plasma cortisol, independent of hypoglycemia, on subsequent counterregulation could be determined.

\section{Day 2 experiments}

Day 2 experiments involved stardardized clamped hypoglycemia to assess the effects of day 1 treatments on subsequent hypoglycemic counterregulation. After a 10-h overnight fast a third glucose clamp study was performed. The timing of the experiment was identical to the previous morning. To measure glucose kinetics, a primed, $(18 \mu \mathrm{Ci})$ constant infusion $(0.18 \mu \mathrm{Ci} / \mathrm{min})$ of $\left[3^{-3} \mathrm{H}\right]$ glucose was started at time $-120 \mathrm{~min}$ and continued throughout the 240 -min experiment. At time zero a primed constant infusion of insulin at a rate of $1.5 \mathrm{mU} / \mathrm{kg}$ per min was started and the rate of fall of plasma glucose and hypoglycemic plateau $(\sim 50 \mathrm{mg} / \mathrm{dl})$ was controlled by a modification of the glucose clamp technique.

The rates of glucose appearance $\left(R_{a}\right)$, hepatic glucose production (HGP), and glucose utilization $\left(\mathrm{R}_{\mathrm{d}}\right)$ were calculated according to the methods of Wall et al. (25). HGP was calculated by determining the total rate of $\mathrm{R}_{\mathrm{a}}$ (this comprises of both endogenous glucose production and exogenous glucose infused to maintain the desired hypoglycemia) and subtracting from it the amount of glucose infused. It is now recognized that this approach is not fully quantitative, as underestimates of total $R_{a}$ and $R_{d}$ can be obtained. The use of a highly purified tracer and taking measurements under steady state conditions (i.e., constant specific activity) in the presence of a low glucose flux minimizes the major problems. Please note that isotopic determinations of glucose turnover were only quantified on day 2. As it is unclear whether tracer infused on day 1 would be stored in glycogen and then released in an uncontrolled fashion during day 2 .

\section{Direct measurement of muscle sympathetic nerve activity}

Microneurographic activity was recorded from the peroneal nerve at the level of the fibular head (26). The approximate location of this nerve was determined by transdermal electrical stimulation $(10-60 \mathrm{~V}$, $0.01 \mathrm{~ms}$ duration). This stimulation produced painless muscle contraction of the foot. After this a reference tungsten electrode, with a shaft diameter of $200 \mu \mathrm{m}$, was placed subcutaneously. A similar electrode, with an uninsulated tip $(1-5 \mu \mathrm{m})$ was inserted into the nerve and used for recording of muscle sympathetic nerve activity. Placement of the recording electrode was guided by electrical stimulation (1-4 V, $0.01 \mathrm{~ms}$ duration). Electrical stimulation was performed with a stimulator (588; Grass Instruments Co., Quincy, MA) connected to an isolation unit (SIU8TB; Grass Instrument Co.).

Recorded signals were fed to a preamplifer $(1,000$-fold amplification) and filtered using a band width between 700 and 2,000 Hz. The filtered signal was rectified, amplified a further 100 -fold, and integrated in a resistance-capacitance network using a time constant of $0.1 \mathrm{~s}$ (Nerve traffic analysis system 662C-3; University of Iowa Bioengineering, Iowa City, IA). The final signal was monitored using a storage oscilloscope (S111A; Tektronix Inc. Beaverton, OR) and recorded after fourfold amplication on a TA-2000 recorder (Gould, Inc., Cleveland, $\mathrm{OH}$ ). A recording of muscle sympathetic nerve activity was considered adequate when $(a)$ electrical stimulation produced muscle twitches but not paresthesia, $(b)$ stretching of the tendons in the foot evoked proprioceptive afferent signals, whereas cutaneous stimulation by slight stroking of the skin did not, $(c)$ nerve activity increased during phase II of the Valsalva maneuver (hypotensive phase) and was suppressed during phase IV (blood pressure overshoot), and $(d)$ nerve activity increased in response to held expira-

Table I. Plasma Glucose, Insulin, and Cortisol Levels from Hyperinsulinemic (1.5 mU/kg per min), Euglycemic and Hypoglycemic Clamp Studies on Morning of Day 1

\begin{tabular}{|c|c|c|c|c|c|c|c|}
\hline & \multirow[b]{2}{*}{ Control period } & \multicolumn{6}{|c|}{ Experimental period } \\
\hline & & 30 & 60 & 75 & 90 & 105 & 120 \\
\hline \multicolumn{8}{|l|}{ Plasma glucose (mg/dl) } \\
\hline Antecedent euglycemia & $95 \pm 1$ & $95 \pm 4$ & $96 \pm 3$ & $96 \pm 3$ & $93 \pm 3$ & $92 \pm 2$ & $93 \pm 3$ \\
\hline Antecedent hypoglycemia & $94 \pm 2$ & $54 \pm 4^{\ddagger}$ & $58 \pm 3^{\ddagger}$ & $56 \pm 3^{\ddagger}$ & $54 \pm 2^{\ddagger}$ & $53 \pm 2^{\ddagger}$ & $52 \pm 2^{\ddagger}$ \\
\hline Antecedent cortisol & $95 \pm 2$ & $96 \pm 3$ & $98 \pm 3$ & $97 \pm 2$ & $92 \pm 2$ & $94 \pm 3$ & $91 \pm 2$ \\
\hline \multicolumn{8}{|l|}{ Plasma insulin $(\mu \mathrm{U} / \mathrm{ml})$} \\
\hline Antecedent euglycemia & $6 \pm 1$ & $98 \pm 4 *$ & $97 \pm 6^{*}$ & $100 \pm 3 *$ & $98 \pm 8^{*}$ & $98 \pm 6^{*}$ & $101 \pm 5^{*}$ \\
\hline Antecedent hypoglycemia & $6 \pm 1$ & $116 \pm 10^{*}$ & $103 \pm 8^{*}$ & $103 \pm 7 *$ & $104 \pm 11 *$ & $105 \pm 8^{*}$ & $107 \pm 13 *$ \\
\hline Antecedent cortisol & $6 \pm 2$ & $101 \pm 10^{*}$ & $97 \pm 10^{*}$ & $98 \pm 9 *$ & $99 \pm 9 *$ & $98 \pm 7 *$ & $99 \pm 9^{*}$ \\
\hline \multicolumn{8}{|l|}{ Plasma cortisol $(\mu \mathrm{g} / \mathrm{dl})$} \\
\hline Antecedent euglycemia & $8 \pm 1$ & $10 \pm 1^{*}$ & $12 \pm 2 *$ & $12 \pm 1^{*}$ & $11 \pm 1^{*}$ & $10 \pm 1^{*}$ & $10 \pm 1 *$ \\
\hline Antecedent hypoglycemia & $8 \pm 1$ & $10 \pm 1^{*}$ & $22 \pm 2 *$ & $25 \pm 2 *$ & $25 \pm 3 *$ & $26 \pm 3^{*}$ & $26 \pm 3 *$ \\
\hline Antededent cortisol & $9 \pm 1$ & $25 \pm 1^{*}$ & $30 \pm 3^{*}$ & $28 \pm 3^{*}$ & $31 \pm 3^{*}$ & $32 \pm 3^{*}$ & $32 \pm 3^{*}$ \\
\hline
\end{tabular}

Values are mean \pm SE. * Plasma insulin and cortisol concentrations are significantly increased $(P<0.05)$ compared with control period. ${ }^{\ddagger}$ Plasma glucose levels are significantly reduced $(P<0.05)$ compared with control period. 
tion. Sympathetic nerve activity will be expressed as bursts/min. Measurements of muscle sympathetic nerve activity (MSNA) were made from the original tracings using a digitizer tablet (HIPAD; Houston Instruments, Austin, TX) coupled to Sigma Scan Software (Jandel Scientific, Coite Modena, CA) in a micro computer. The effect of a given antecedent treatment on MSNA was expressed as change $(\Delta)$ from preceeding control period.

Two types of sympathetic fibers (skin and muscle) can be identified from recordings of peripheral nerves. MSNA was recorded in the present study as this has been demonstrated to reflect increased sympathetic activity during insulin-induced hypoglycemia (27), 2-deoxyglucose-induced neuroglycopenia, (28) and hyperinsulinemic euglycemia in normal humans (29).

Microneurography is a particularly useful technique and has several advantages in assessing sympathetic neuronal activity compared
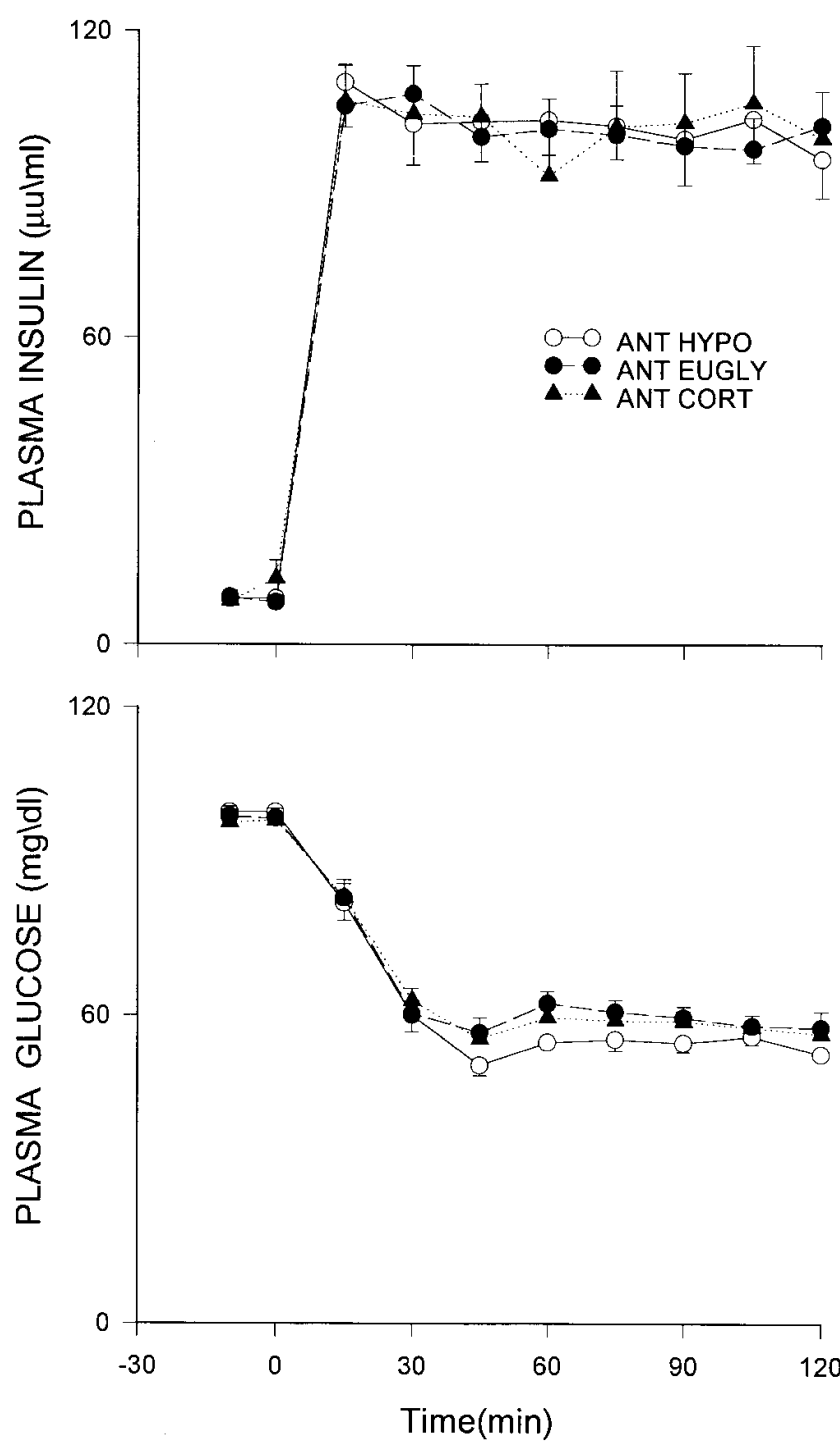

Figure 2. Effects of peripherally infused insulin ( $1.5 \mathrm{mU} / \mathrm{kg}$ per min) on arterialized plasma insulin and glucose levels in overnight fasted man after antecedent hyperinsulinemic-euglycemia $(\bigcirc-\bigcirc)$, antecedent hyperinsulinemic-hypoglycemia (-@), and antecedent hyperinsulinemic-euglycemia with simulated cortisol $(\boldsymbol{\Delta}-\mathbf{\Lambda})$. Plasma insulin concentrations during each infusion were significantly different $(P<0.01)$ from control period at $15 \mathrm{~min}$ onward. Plasma glucose concentrations were significantly different from control period values at $15 \min (P<0.01)$ onward. to assays of circulating catecholamines. Measurement of norepinephrine levels in humans does not accurately reflect the concentrations occurring at the synaptic cleft. In fact, due to reuptake mechanisms in the synaptic cleft and clearance in the gut and liver, only a small fraction of the available norepinephrine is measured peripherally. Consequently circulating norepinephrine levels provide a small and imprecise reflection of sympathetic nervous system activity (30). Thus measurements of arterial norepinephrine underestimate the degree of sympathetic activation induced by hypotension when compared with measurements of muscle sympathetic nerve activity (31). Additionally, it has been demonstrated that hyperinsulinemia may increase norepinephrine clearance, thereby giving falsely low cate-
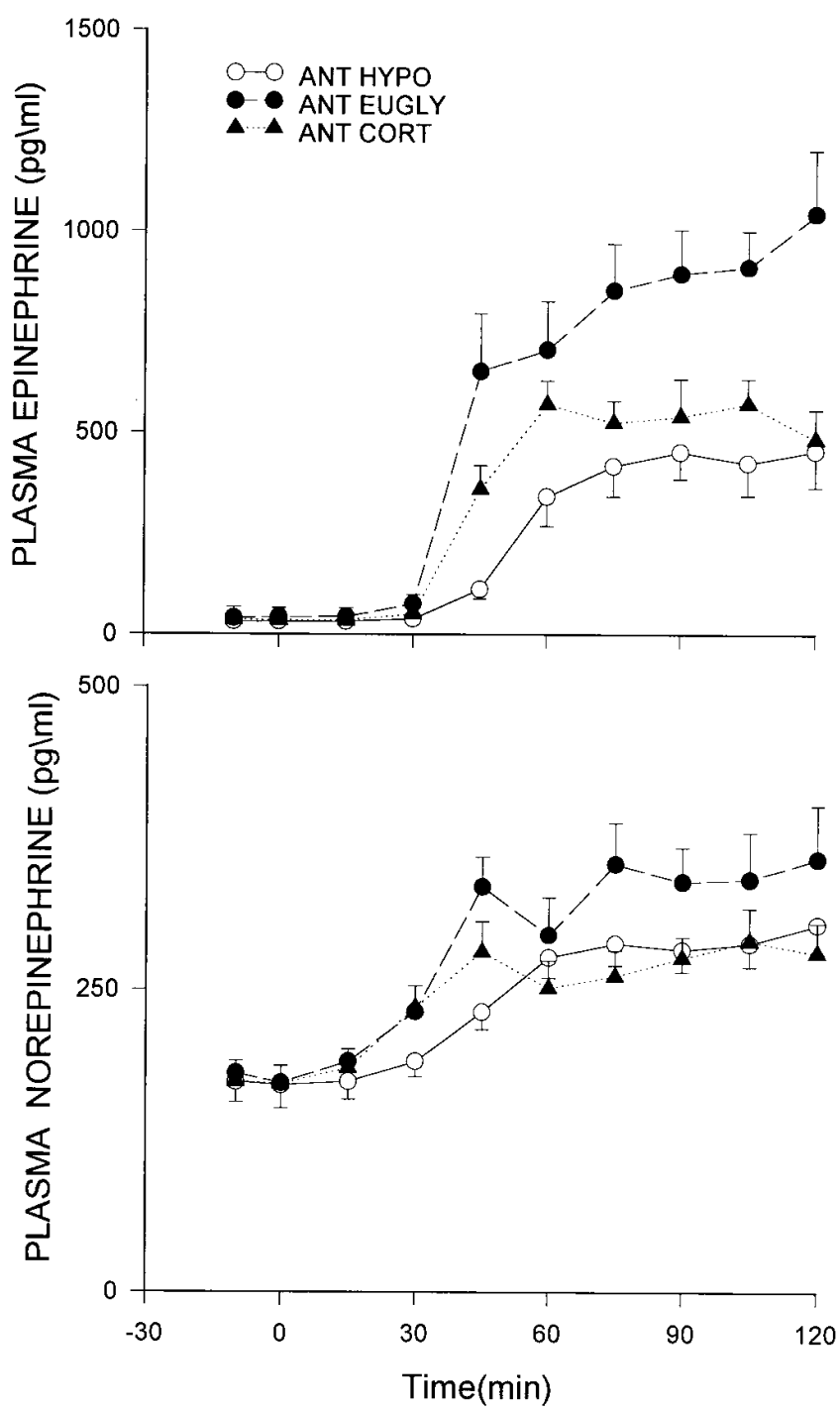

Figure 3. Effects of peripherally infused insulin ( $1.5 \mathrm{mU} / \mathrm{kg}$ per min) on arterialized plasma epinephrine and norepinephrine levels in overnight fasted man. Symbols are as indicated for Fig. 2. Plasma epinephrine was initially significantly increased $(P<0.01)$ from control values at $45 \mathrm{~min}$ onward during all protocols. Antecedent hypoglycemia and antecedent cortisol values are significantly lower $(P<0.01)$ compared with antecedent euglycemia. Plasma norepinephrine was initially significantly increased $(P<0.05)$ from control values at 30 min onward during antecedent euglycemia and antecedent cortisol but $45 \mathrm{~min}$ during antecedent hypoglycemia. Antecedent hypoglycemia and antecedent cortisol values are significantly lower $(P<0.05)$ compared with antecedent euglycemia. 
cholamine levels (32). Therefore, by combining microneurography with assays for circulating catecholamines, a more accurate estimation of sympathetic activity is obtained.

\section{Analytical methods}

The collection and processing of blood samples have been described elsewhere (33). Plasma glucose concentrations were measured in triplicate using the glucose oxidase method with a glucose analyzer (Beckman Instruments, Inc., Fullerton, CA). Glucagon was measured according to the method of Aguilar-Parada et al. with an interassay coefficient of variation (CV) of $15 \%$ (34). Insulin was measured as described previously (35) with an interassay CV of $11 \%$. Catecholamines were determined by HPLC (36) with an interassay CV of $17 \%$ for epinephrine and $14 \%$ for norepinephrine. We made two modifica-
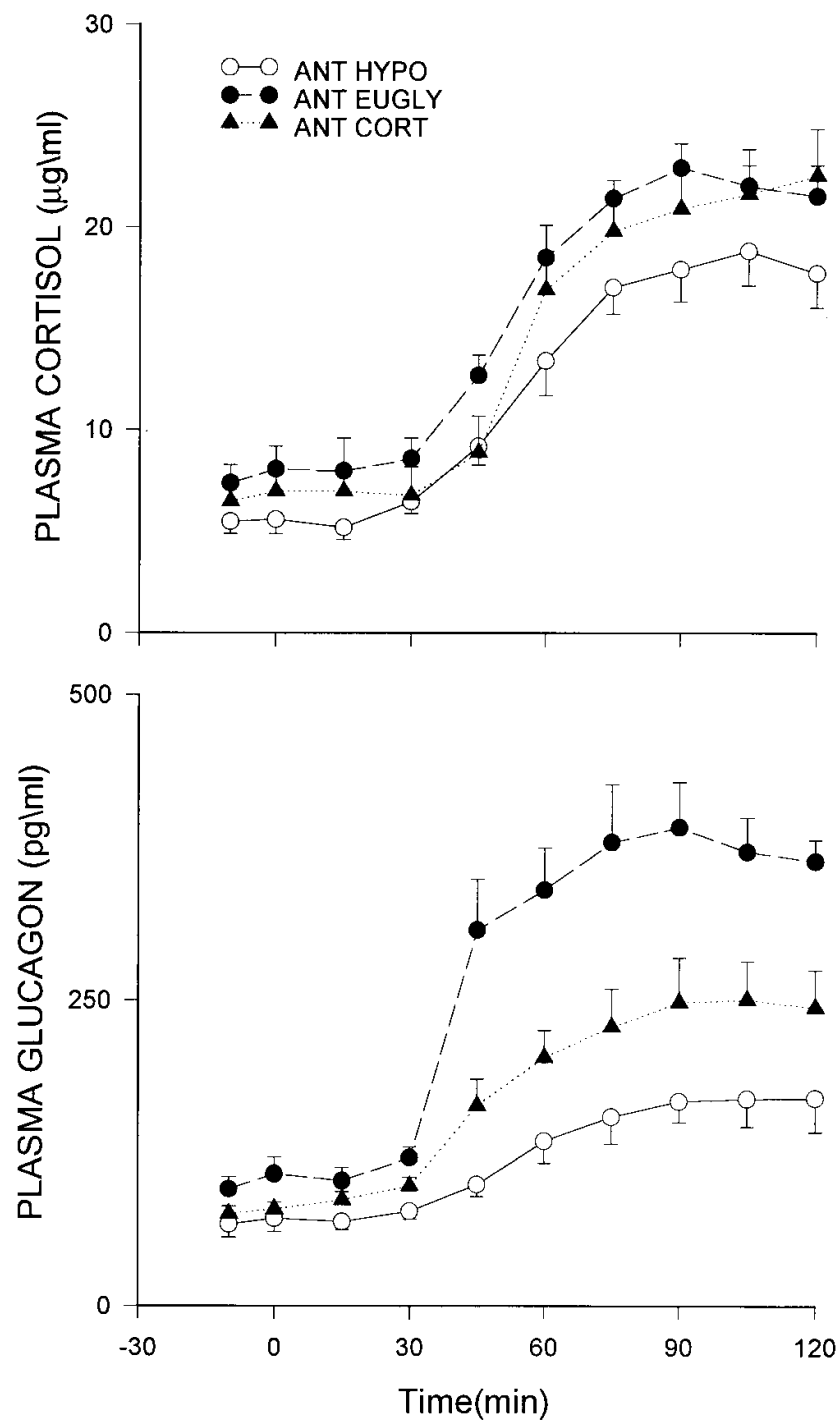

Figure 4. Effects of peripherally infused insulin (1.5 mU/kg per min) on arterialized plasma cortisol and glucagon levels in overnight fasted man. Symbols are as indicated for Fig. 2. Plasma cortisol was initially significantly increased $(P<0.05)$ from control values at 45 min onwards in all protocols. Plasma glucagon was initially significantly increased $(P<0.05)$ from control values at $45 \mathrm{~min}$ onward in all protocols. Antecedent hypoglycemia values are significantly lower compared with antecedent euglycemia $(P<0.01)$ and antecedent cortisol $(P<0.05)$. Antecedent cortisol values are significantly lower $(P<0.01)$ compared with antecedent euglycemia. tions to the procedure for catecholamine determination: $(a)$ we used a five rather than one-point standard calibration curve; and $(b)$ we spiked the initial and final samples of plasma with known amounts of epinephrine and norepinephrine so accurate identification of the relevant respective catecholamine peaks could be made. Cortisol was assayed by using the Clinical Assays Gamma Coat RIA kit with an interassay $\mathrm{CV}$ of $6 \%$. Growth hormone was determined by RIA (37) with a CV of $8.6 \%$. Pancreatic polypeptide was measured by RIA using the method of Hagopian et al. (38) with an interassay $\mathrm{CV}$ of $8 \%$. Adrenocorticotropin $(\mathrm{ACTH})$ and $\beta$-endorphin were determined by RIA with a CV of $10 \%$ using the method of Nicholson et al. (39).

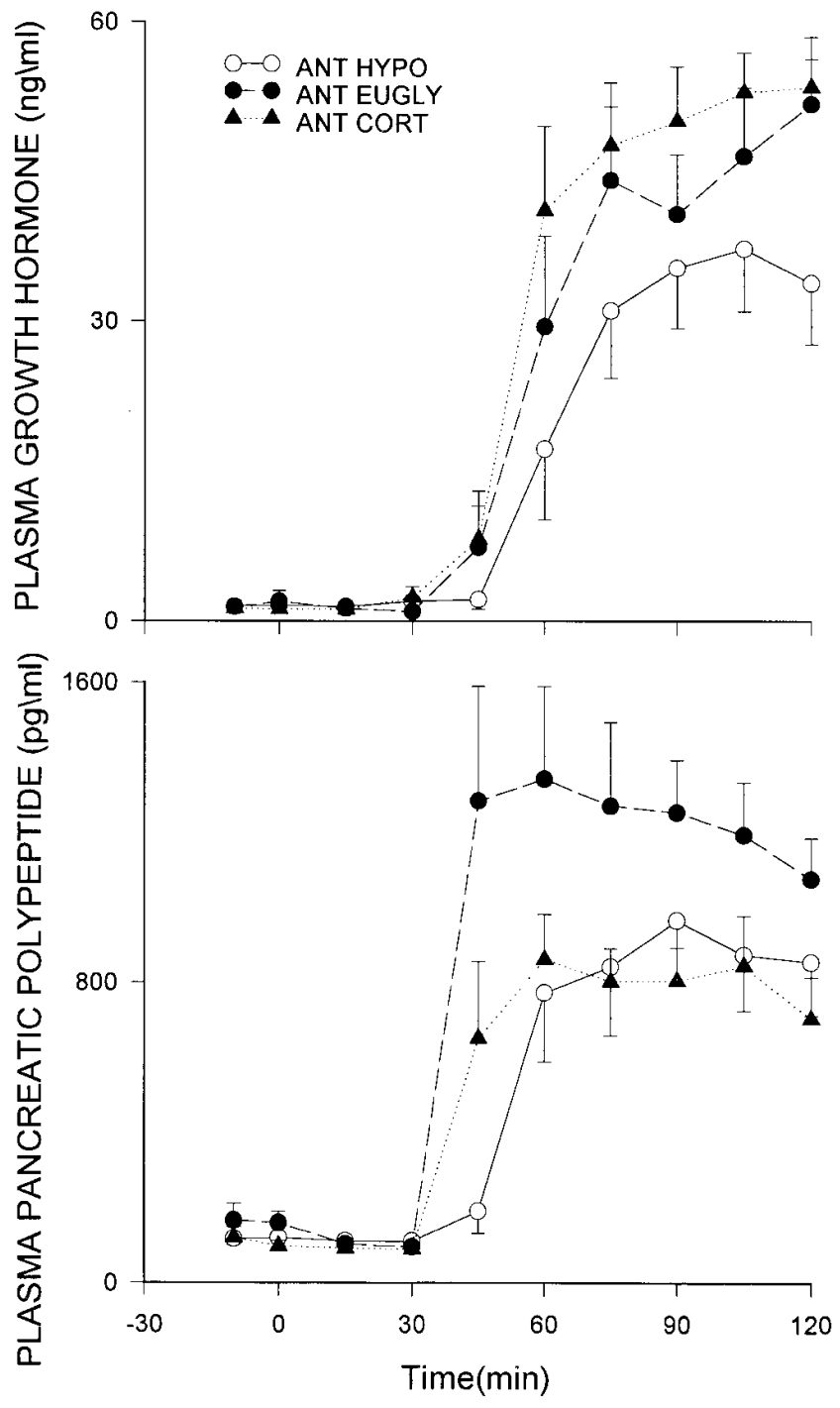

Figure 5. Effects of peripherally infused insulin $(1.5 \mathrm{mU} / \mathrm{kg}$ per $\mathrm{min})$ on arterialized plasma growth hormone and pancreatic polypeptide levels in overnight fasted man. Symbols are as indicated for Fig. 2. Plasma growth hormone was initially significantly increased $(P<$ 0.05 ) from control values at 45 min onward during antecedent euglycemia and antecedent cortisol but 60 min during antecedent hypoglycemia. Antecedent hypoglycemia values are significantly lower $(P<$ $0.05)$ compared to antecedent euglycemia or antecedent cortisol. Plasma pancreatic polypeptide was initially significantly increased $(P<0.05)$ from control values at 45 min onward during antecedent euglycemia and antecedent cortisol but 60 min during antecedent hypoglycemia. Antecedent cortisol and antecedent hypoglycemia values are significantly lower $(P<0.01)$ compared with antecedent euglycemia. 
Lactate, glycerol, alanine, and 3-hydroxybutyrate were measured on deproteinized whole blood using the method of Lloyd et al. (40). Nonesterified fatty acids were measured using the Wako Bioproducts kit (Richmond, VA) adopted for use on a centrifugal analyzer (41).

Blood samples for glucose flux were taken every 10 min throughout the control period and every 15 min during the experimental period. Blood for hormones and intermediary metabolites were drawn two times during the control period and every 15 min during the experimental period. Cardiovascular parameters (pulse, systolic, diastolic, and mean arterial pressure) were measured noninvasively by a Dinamap (Critikon, Tampa, FL) every 10 min throughout each 300-
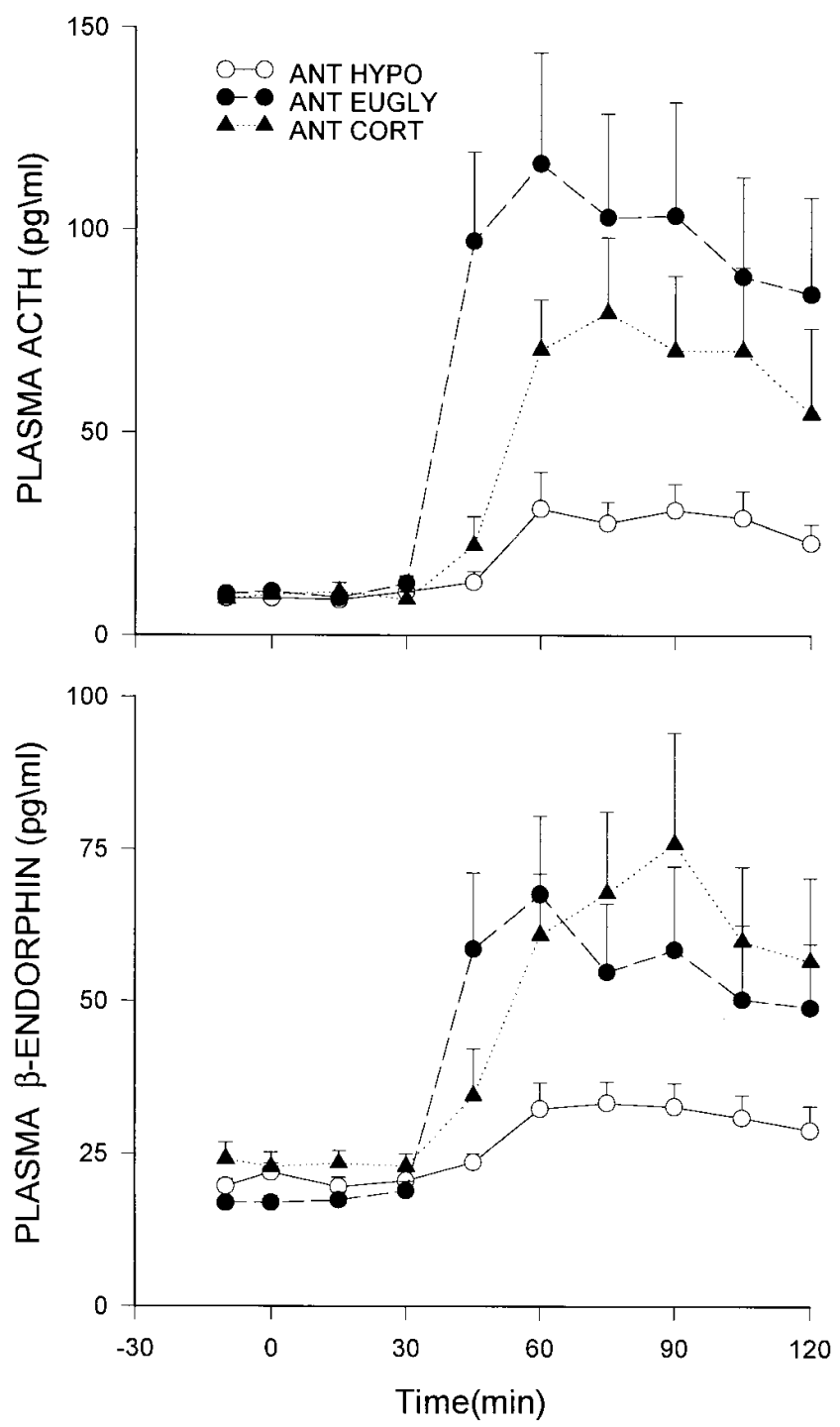

Figure 6. Effects of peripherally infused insulin ( $1.5 \mathrm{mU} / \mathrm{kg}$ per min) on arterialized plasma ACTH and $\beta$-endorphin levels in overnight fasted man. Symbols are as indicated for Fig. 2. Plasma ACTH was initially significantly increased $(P<0.05)$ from control values at 45 min onward during antecedent euglycemia and antecedent cortisol but 60 min during antecedent hypoglycemia. Antecedent hypoglycemia values are significantly lower compared with antecedent cortisol $(P<0.01)$ and antecedent euglycemia $(P<0.01)$. Plasma $\beta$-endorphin was initially significantly increased $(P<0.05)$ from control values at 45 min onwards during antecedent euglycemia and antecedent cortisol, but 60 min during antecedent hypoglycemia. Antecedent hypoglycemia values are significantly lower $(P<0.01)$ compared with antecedent cortisol or antecedent euglycemia. min study. MSNA was measured continuously throughout each 300min study.

\section{Materials}

HPLC purified $\left[3{ }^{3} \mathrm{H}\right]$ glucose (New England Nuclear, Boston, MA) was used as the glucose tracer $(11.5 \mathrm{mCi} / \mathrm{mM})$. Human regular insulin was purchased from Eli Lilly and Co. (Indianapolis, IN). The insulin infusion solution was prepared with normal saline and contained $3 \%$ ( $\mathrm{vol} / \mathrm{vol})$ of the subject's own plasma. Hydrocortisone was purchased from Organon, Inc. (West Orange, NJ).

\section{Statistical analysis}

Data are expressed as mean \pm SE unless otherwise stated, and analyzed using standard, parametric, two-way ANOVA with a repeated measures design. This was coupled with a paired or unpaired Student's $t$ test to delineate at which time statistical significance was reached. A $P$ value of $<0.05$ indicated significant difference.

\section{Results}

Insulin, glucose, and cortisol levels from day 1 morning studies. Peripheral insulin values were stable and at similar steady state levels by the final 45 min of each experimental protocol (Table I). Plasma glucose levels (Table I) were also stable during the final $45 \mathrm{~min}$ of each experiment with a $\mathrm{CV}$ of 1.9, 3.2, and $2.4 \%$ during antecedent euglycemia, hypoglycemia, and cortisol respectively. Plasma cortisol levels (Table I) increased

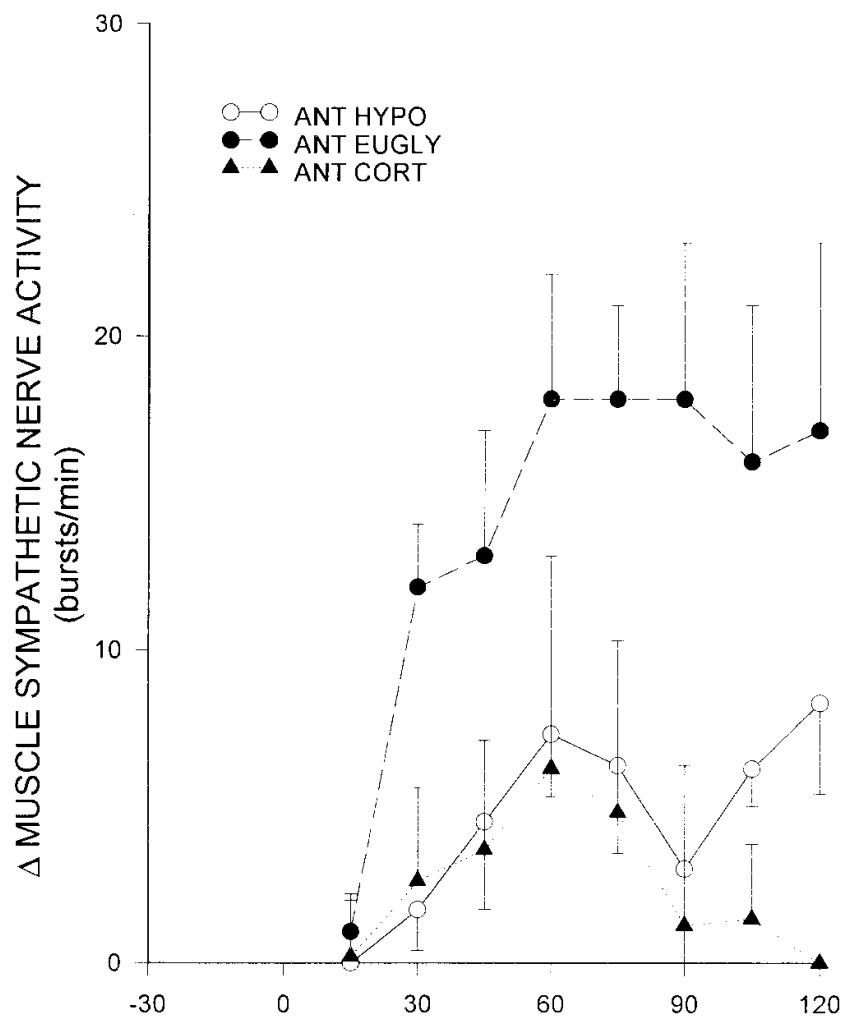

Figure 7. Effects of peripherally infused insulin ( $1.5 \mathrm{mU} / \mathrm{kg}$ per min) on incremental increase from baseline MSNA in overnight fasted man. Symbols are as indicated for Fig. 2. MSNA was initially significantly increased $(P<0.05)$ from control values at $30 \mathrm{~min}$ onward during antecedent euglycemia but 60 min during antecedent hypoglycemia and antecedent cortisol. Antecedent hypoglycemia and antecedent cortisol values are significantly lower $(P<0.01)$ compared with antecedent euglycemia. 
Table II. Effects of Antecedent (Day 1) Hyperinsulinemic Euglycemia, Hypoglycemia, and Hyperinsulinemic Euglycemia plus Cortisol on Glucose Turnover during Day 2 Hypoglycemia $(53 \pm 2 \mathrm{mg} / \mathrm{dl})$

\begin{tabular}{|c|c|c|c|c|c|}
\hline & \multirow[b]{2}{*}{ Control period } & \multicolumn{4}{|c|}{ Final 45 min of clamped hypoglycemia } \\
\hline & & 195 & 210 & 225 & 240 \\
\hline \multicolumn{6}{|c|}{ Hepatic glucose production (mg/kg per min) } \\
\hline Antecedent euglycemia & $1.9 \pm 0.1$ & $1.8 \pm 0.1$ & $1.8 \pm 0.1$ & $1.9 \pm 0.1$ & $1.9 \pm 0.1$ \\
\hline Antecedent hypoglycemia & $2.1 \pm 0.1$ & $1.3 \pm 0.3^{\ddagger}$ & $1.2 \pm 0.3^{\ddagger}$ & $1.2 \pm 0.2^{\ddagger}$ & $1.1 \pm 0.3^{\ddagger}$ \\
\hline Antecedent cortisol & $2.0 \pm 0.1$ & $1.7 \pm 0.1 *$ & $1.6 \pm 0.1 *$ & $1.6 \pm 0.2 *$ & $1.6 \pm 0.1 *$ \\
\hline \multicolumn{6}{|c|}{ Glucose utilization (mg/kg per min) } \\
\hline Antecedent euglycemia & $1.9 \pm 0.2$ & $2.0 \pm 0.1$ & $1.9 \pm 0.1$ & $1.9 \pm 0.1$ & $2.0 \pm 0.1$ \\
\hline Antecedent hypoglycemia & $2.0 \pm 0.2$ & $1.9 \pm 0.1$ & $1.8 \pm 0.1$ & $1.9 \pm 0.2$ & $1.8 \pm 0.2$ \\
\hline Antecedent cortisol & $2.0 \pm 0.1$ & $1.9 \pm 0.1$ & $1.8 \pm 0.1$ & $1.8 \pm 0.2$ & $1.9 \pm 0.2$ \\
\hline \multicolumn{6}{|c|}{ Glucose specific activity (dpm/mg) } \\
\hline Antecedent euglycemia & $80 \pm 5$ & $88 \pm 8$ & $87 \pm 7$ & $89 \pm 7$ & $88 \pm 7$ \\
\hline Antecedent hypoglycemia & $85 \pm 7$ & $80 \pm 7$ & $81 \pm 6$ & $80 \pm 6$ & $83 \pm 7$ \\
\hline Antecedent cortisol & $82 \pm 15$ & $97 \pm 12$ & $97 \pm 12$ & $101 \pm 13$ & $100 \pm 12$ \\
\hline \multicolumn{6}{|c|}{ Glucose infusion rate (mg/kg per min) } \\
\hline Antecedent euglycemia & & 0 & 0 & 0 & 0 \\
\hline Antecedent hypoglycemia & & $0.6 \pm 0.3$ & $0.6 \pm 0.4$ & $0.7 \pm 0.4$ & $0.7 \pm 0.4$ \\
\hline Antecedent cortisol & & $0.2 \pm 0.1$ & $0.2 \pm 0.1$ & $0.2 \pm 0.1$ & $0.3 \pm 0.2$ \\
\hline
\end{tabular}

Values are mean \pm SE. *Final 45 min values suppressed $(P<0.05)$ compared with control period. ${ }^{\ddagger}$ Final 45 min values reduced $(P<0.05)$ compared with antecedent euglycemia or cortisol.

by a modest but significant amount (ANOVA $P<0.05)$ during hyperinsulinemic euglycemia. In response to hypoglycemia cortisol levels increased about threefold reaching steady state level of $26 \pm 3 \mu \mathrm{g} / \mathrm{dl}$ during the final $45 \mathrm{~min}$ of experiments. During antecedent cortisol studies, plasma cortisol levels were initially higher than antecedent hypoglycemia protocols but reached similar steady state levels $(31 \pm 3 \mu \mathrm{g} / \mathrm{dl})$ by the final 45 min of each experiment (Table I).

Insulin, glucose, and neuroendocrine hormones from day 2 morning studies. Insulin infusions resulted in equivalent steady state levels by $30 \mathrm{~min}$ in all group (Fig. 2). During the final 45 min of each experiment peripheral insulin levels were stable

Table III. Effects of Antecedent (Day 1) Hyperinsulinemic Euglycemia, Hypoglycemia, and Hyperinsulinemic-euglycemia plus Cortisol on Cardiovascular Parameters during Day 2 Hypoglycemia $(53 \pm 2 \mathrm{mg} / \mathrm{dl})$

\begin{tabular}{|c|c|c|c|c|c|}
\hline & \multirow[b]{2}{*}{ Control period } & \multicolumn{4}{|c|}{ Final 45 min of clamped hypoglycemia } \\
\hline & & 195 & 210 & 225 & 240 \\
\hline \multicolumn{6}{|c|}{ Systolic blood pressure (mmHg) } \\
\hline Antecedent euglycemia & $117 \pm 4$ & $130 \pm 6^{*}$ & $131 \pm 7 *$ & $131 \pm 6^{*}$ & $131 \pm 7 *$ \\
\hline Antecedent hypoglycemia & $120 \pm 3$ & $128 \pm 4 *$ & $134 \pm 4 *$ & $131 \pm 4 *$ & $135 \pm 5^{*}$ \\
\hline Antecedent cortisol & $114 \pm 4$ & $126 \pm 6^{*}$ & $131 \pm 6^{*}$ & $125 \pm 6^{*}$ & $125 \pm 7 *$ \\
\hline \multicolumn{6}{|c|}{ Diastolic blood pressure $(\mathrm{mmHg})$} \\
\hline Antecedent euglycemia & $67 \pm 4$ & $60 \pm 3$ & $59 \pm 3$ & $60 \pm 3$ & $60 \pm 5$ \\
\hline Antecedent hypoglycemia & $63 \pm 2$ & $57 \pm 2$ & $56 \pm 3$ & $57 \pm 3$ & $60 \pm 3$ \\
\hline Antecedent cortisol & $65 \pm 3$ & $58 \pm 4$ & $56 \pm 3$ & $57 \pm 4$ & $58 \pm 4$ \\
\hline \multicolumn{6}{|c|}{ Mean arterial pressure $(\mathrm{mmHg})$} \\
\hline Antecedent euglycemia & $83 \pm 3$ & $84 \pm 4$ & $83 \pm 4$ & $84 \pm 4$ & $84 \pm 5$ \\
\hline Antecedent hypoglycemia & $82 \pm 2$ & $81 \pm 2$ & $82 \pm 3$ & $81 \pm 3$ & $84 \pm 3$ \\
\hline Antecedent cortisol & $81 \pm 3$ & $80 \pm 3$ & $81 \pm 48$ & $80 \pm 3$ & $81 \pm 4$ \\
\hline \multicolumn{6}{|l|}{ Heart rate (beats/min) } \\
\hline Antecedent euglycemia & $63 \pm 4$ & $78 \pm 6^{*}$ & $77 \pm 6^{*}$ & $78 \pm 4 *$ & $76 \pm 6^{*}$ \\
\hline Antecedent hypoglycemia & $61 \pm 3$ & $71 \pm 5^{*}$ & $71 \pm 5$ & $69 \pm 4 *$ & $71 \pm 4 *$ \\
\hline Antecedent cortisol & $60 \pm 4$ & $71 \pm 4 *$ & $68 \pm 3 *$ & $68 \pm 4 *$ & $68 \pm 4^{*}$ \\
\hline
\end{tabular}

Values are mean \pm SE. *Final 45 min values are significantly increased $(P<0.01)$ compared with control period. 
(CV of $2.4 \%$ ) at $99 \pm 5 \mu \mathrm{U} / \mathrm{ml}$. Plasma glucose levels fell at an equivalent rate $(1.1 \mathrm{mg} / \mathrm{min})$ in all studies and reached a similar steady state hypoglycemic plateau of $55 \pm 3 \mathrm{mg} / \mathrm{dl}$. The stability of the plasma glucose level during the last $45 \mathrm{~min}$ of each protocol was demonstrated by a CV of $2.3 \%$.

In response to hypoglycemia, plasma levels of all neuroendocrine hormones (epinephrine, norepinephrine, cortisol, growth hormone, glucagon, pancreatic polypeptide, $\beta$-endorphin, and ACTH) increased compared to baseline $(P<0.01)$. Despite similar hypoglycemia there were significant differences $(P<0.01)$ in epinephrine levels (Fig. 3) among groups. Epinephrine levels were significantly reduced $(P<0.01)$ during the final $45 \mathrm{~min}$ of antecedent hypoglycemia $(450 \pm 81 \mathrm{pg} /$ $\mathrm{ml})$ and antecedent cortisol experiments $(530 \pm 76 \mathrm{pg} / \mathrm{ml})$ compared with antecedent euglycemia $(950 \pm 94 \mathrm{pg} / \mathrm{ml})$. There was no overall statistical difference between epinephrine levels after antecedent hypoglycemia or cortisol. However, epinephrine levels increased more briskly in response to hypoglycemia after antecedent cortisol than antecedent hypoglycemia. There were also significant differences in norepinephrine levels (Fig. $3)$ among groups. Norepinephrine levels were significantly suppressed $(P<0.05)$ after antecedent hypoglycemia $(291 \pm 20$ $\mathrm{pg} / \mathrm{ml})$ and antecedent cortisol experiments $(275 \pm 23 \mathrm{pg} / \mathrm{ml})$ compared with antecedent euglycemia $(348 \pm 35 \mathrm{pg} / \mathrm{ml})$. There was no statistical difference between norepinephrine levels in the antecedent hypoglycemia or cortisol groups. However, similar to epinephrine results, norepinephrine levels increased more rapidly to hypoglycemia after antecedent cortisol com- pared with previous hypoglycemia. Plasma cortisol (Fig. 4) levels increased similarly in all groups. A difference in baseline values tended to accentuate a small nonsignificant difference between antecedent hypoglycemia and the other two groups.

There were significant differences $(P<0.01)$ in glucagon (Fig. 4) among groups. After antecedent hypoglycemia (165士 $22 \mathrm{pg} / \mathrm{ml})$ or antecedent cortisol $(243 \pm 32 \mathrm{pg} / \mathrm{ml})$, plasma glucagon levels were significantly suppressed $(P<0.01)$ compared with antecedent euglycemia $(376 \pm 33 \mathrm{pg} / \mathrm{ml})$. Plasma glucagon levels were significantly higher $(P<0.05)$ after antecedent cortisol compared with previous hypoglycemia $(243 \pm 32$ vs $165 \pm 22 \mathrm{pg} / \mathrm{ml}, P<0.05)$.

Plasma growth hormone levels (Fig. 5) were significantly suppressed $(P<0.05)$ after antecedent hypoglycemia $(34 \pm 6$ $\mathrm{ng} / \mathrm{ml}$ ) compared with either antecedent euglycemia $(46 \pm 6 \mathrm{pg} /$ $\mathrm{ml})$ or antecedent cortisol $(51 \pm 5 \mathrm{ng} / \mathrm{ml})$. There was no difference in growth hormone levels after antecedent euglycemia or cortisol. There were significant differences $(P<0.01)$ in plasma pancreatic polypeptide (Fig. 5) levels among groups. Pancreatic polypeptide levels were significantly suppressed $(P<$ $0.05)$ after both antecedent hypoglycemia $(882 \pm 161 \mathrm{pg} / \mathrm{ml})$ or cortisol $(787 \pm 106 \mathrm{pg} / \mathrm{ml})$ compared to antecedent euglycemia $(1,198 \pm 151 \mathrm{pg} / \mathrm{ml})$. Pancreatic polypeptide levels were similar after antecedent hypoglycemia or previous cortisol. Plasma ACTH levels were also significantly different $(P<0.01)$ among groups. ACTH levels (Fig. 6) were suppressed $(P<$ $0.05)$ after antecedent hypoglycemia $(28 \pm 6 \mathrm{pg} / \mathrm{ml})$ or antecedent cortisol $(68 \pm 20 \mathrm{pg} / \mathrm{ml})$ compared with previous euglyce-

Table IV. Effects of Antecedent (Day 1) Hyperinsulinemic Euglycemia, Hypoglycemia and Hyperinsulinemic-euglycemia plus Cortisol on Intermediary Metabolites during Day 2 Hypoglycemia $(53 \pm 2 \mathrm{mg} / \mathrm{dl})$

\begin{tabular}{|c|c|c|c|c|c|}
\hline & \multirow[b]{2}{*}{ Control period } & \multicolumn{4}{|c|}{ Final 45 min of clamped hypoglycemia } \\
\hline & & 195 & 210 & 225 & 240 \\
\hline \multicolumn{6}{|l|}{ Blood lactate $(\mu \mathrm{m})$} \\
\hline Antecedent euglycemia & $924 \pm 101$ & $1,612 \pm 102 *$ & $1,785 \pm 123^{*}$ & $1,902 \pm 142 *$ & $2,055 \pm 163 *$ \\
\hline Antecedent hypoglycemia & $945 \pm 96$ & $1,438 \pm 83^{* \ddagger}$ & $1,527 \pm 64^{* \ddagger}$ & $1,498 \pm 64 * \neq$ & $1,579 \pm 87 * \neq$ \\
\hline Antecedent cortisol & $998 \pm 58$ & $1,683 \pm 111^{* \ddagger}$ & 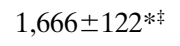 & $1,616 \pm 145^{* \ddagger}$ & $1,737 \pm 149 *$ \\
\hline \multicolumn{6}{|l|}{ Blood alanine $(\mu \mathrm{m})$} \\
\hline Antecedent euglycemia & $350 \pm 38$ & $317 \pm 26$ & $323 \pm 30$ & $311 \pm 29$ & $304 \pm 26$ \\
\hline Antecedent hypoglycemia & $368 \pm 30$ & $325 \pm 17^{\S}$ & $317 \pm 14^{\S}$ & $304 \pm 14^{\S}$ & $296 \pm 17^{\S}$ \\
\hline Antecedent cortisol & $407 \pm 32^{\S}$ & $366 \pm 19^{\S}$ & $349 \pm 23^{\S}$ & $328 \pm 20^{\S}$ & $316 \pm 14^{\S}$ \\
\hline \multicolumn{6}{|l|}{ Blood glycerol $(\mu \mathrm{m})$} \\
\hline Antecedent euglycemia & $32 \pm 1$ & $25 \pm 2$ & $24 \pm 1$ & $30 \pm 5$ & $28 \pm 5$ \\
\hline Antecedent hypoglycemia & $35 \pm 2$ & $25 \pm 1^{\S}$ & $24 \pm 1^{\S}$ & $25 \pm 2^{\S}$ & $26 \pm 2^{\S}$ \\
\hline Antecedent cortisol & $35 \pm 5$ & $24 \pm 2^{\S}$ & $21 \pm 3^{\S}$ & $25 \pm 4^{\S}$ & $28 \pm 3^{\S}$ \\
\hline \multicolumn{6}{|c|}{ Blood 3-hydroxybutyrate $(\mu \mathrm{m})$} \\
\hline Antecedent euglycemia & $35 \pm 13$ & $11 \pm 2^{\S}$ & $10 \pm 2^{\S}$ & $10 \pm 2^{\S}$ & $8 \pm 2^{\S}$ \\
\hline Antecedent hypoglycemia & $28 \pm 5$ & $7 \pm 2^{\S}$ & $8 \pm 3^{\S}$ & $8 \pm 3^{\S}$ & $7 \pm 2^{\S}$ \\
\hline Antecedent cortisol & $27 \pm 10$ & $11 \pm 2^{\S}$ & $10 \pm 1^{\S}$ & $8 \pm 1^{\S}$ & $8 \pm 1^{\S}$ \\
\hline \multicolumn{6}{|l|}{ Plasma NEFA $(\mu \mathrm{m})$} \\
\hline Antecedent euglycemia & $384 \pm 100$ & $194 \pm 39^{\S}$ & $180 \pm 34^{\S}$ & $170 \pm 28^{\S}$ & $183 \pm 35^{\S}$ \\
\hline Antecedent hypoglycemia & $492 \pm 45$ & $211 \pm 24^{\S}$ & $201 \pm 24^{\S}$ & $192 \pm 21^{\S}$ & $205 \pm 15^{\S}$ \\
\hline Antecedent cortisol & $419 \pm 43$ & $211 \pm 11^{\S}$ & $203 \pm 13^{\S}$ & $203 \pm 11^{\S}$ & $210 \pm 16^{\S}$ \\
\hline
\end{tabular}

Values are means \pm SE. *Final 45 min values are significantly increased $(P<0.01)$ compared with control period. "Incremental increase in lactate values are reduced $(P<0.05)$ compared with antecedent euglycemia. ${ }^{8}$ Final 45 min values are significantly lower $(P<0.05)$ compared with control period. 
mia $(95 \pm 25 \mathrm{pg} / \mathrm{ml})$. ACTH levels were suppressed by a relatively greater amount $(P<0.05)$ after antecedent hypoglycemia compared to antecedent cortisol. Plasma $\beta$-endorphin (Fig. 6) levels were significantly suppressed $(P<0.01)$ after antecedent hypoglycemia $(31 \pm 4 \mathrm{pg} / \mathrm{ml})$ compared with either antecedent euglycemia $(53 \pm 11 \mathrm{pg} / \mathrm{ml})$ or antecedent cortisol $(65 \pm 14 \mathrm{pg} / \mathrm{ml})$. There were no differences in $\beta$-endorphin levels after antecedent euglycemia or cortisol.

Direct muscle sympathetic nerve activity. Due to large intersubject variation MSNA will be reported as incremental increases from baseline (Fig. 7). There were significant differences $(P<0.01)$ in MSNA among groups. MSNA was significantly suppressed $(P<0.01)$ after antecedent hypoglycemia $(+6 \pm 3$ bursts/min) or cortisol $(+2 \pm 2$ bursts $/ \mathrm{min})$ compared to previous euglycemia $(+18 \pm 4$ bursts/min). There were no differences in MSNA after day 1 hypoglycemia or cortisol.

Glucose flux. Glucose specific activity $(\mathrm{dpm} / \mathrm{mg})$ was in a similar steady state during the control period of each experimental group (antecedent euglycemia $\mathrm{CV}=2.0 \%$; antecedent hypoglycemia $\mathrm{CV}=4.1 \%$; antecedent cortisol $\mathrm{CV}=2.2 \%$ ). By the final $45 \mathrm{~min}$ of each insulin infusion period, an isotopic steady state existed with a CV of $0.9,1.7$, and $2.1 \%$ for antecedent euglycemia, hypoglycemia, and cortisol, respectively. Hepatic glucose production (Table II) was initially similar $(2.0 \pm 0.1 \mathrm{mg} / \mathrm{kg}$ per $\mathrm{min})$ in all groups. Hepatic glucose production remained unchanged after antecedent euglycemia, but declined to $1.6 \pm 0.1 \mathrm{mg} / \mathrm{kg}$ per $\min$ and $1.2 \pm 0.3 \mathrm{mg} / \mathrm{kg}$ per $\min (P<$ 0.02 ) by the final $45 \mathrm{~min}$ of antecedent cortisol and hypoglycemia experiments, respectively. After antecedent euglycemia no exogenous glucose was required to maintain plasma glucose at the desired hypoglycemic level during day 2 experiments. Day 2 exogenous glucose infusions in the other two groups were minimal with only a rate of $0.2 \pm 0.1 \mathrm{mg} / \mathrm{kg}$ per min after antecedent cortisol experiments and $0.7 \pm 0.4 \mathrm{mg} / \mathrm{kg}$ per min after antecedent hypoglycemia studies. Glucose utilization rates were similar during the final $45 \mathrm{~min}$ of each experimental group (antecedent euglycemia 2.0 \pm 0.1 , antecedent hypoglycemia $2.1 \pm 0.2$, and antecedent cortisol $1.9 \pm 0.2 \mathrm{mg} / \mathrm{kg}$ per min).

Cardiovascular parameters. Heart rate, systolic, diastolic, and mean arterial blood pressure were similar at the start of each study (Table III). Despite large differences in circulating catecholamine levels and MSNA between groups, heart rate, systolic, diastolic, and mean arterial pressure responded similarly during day 2 hypoglycemic clamp studies (Table III).

Intermediary metabolism. There was a significant difference $(P<0.01)$ in blood lactate responses among groups (Table IV). Blood lactate levels were increased significantly $(P<$ 0.01 ) by the final $45 \mathrm{~min}$ of each experimental group. However, incremental increases in blood lactate after antecedent hypoglycemia $(+565 \pm 60 \mu \mathrm{M})$ or antecedent cortisol $(+680 \pm$ $85 \mu \mathrm{M})$ were significantly blunted $(P<0.05)$ compared with antecedent euglycemia $(+915 \pm 95 \mu \mathrm{M})$. There was also a significant difference $(P<0.05)$ in blood alanine responses among groups. Alanine levels remained similar to baseline after antecedent euglycemia $(350 \pm 38$ to $314 \pm 27 \mu \mathrm{M})$ but were suppressed significantly $(P<0.05)$ after antecedent hypoglycemia $(368 \pm 30$ to $311 \pm 15 \mu \mathrm{M})$ and antecedent cortisol $(407 \pm 31$ to $340 \pm 18 \mu \mathrm{M})$. There were also significant $(P<$ $0.02)$ differences in glycerol metabolism among groups. Blood glycerol levels remained similar to baseline after antecedent euglycemia ( $32 \pm 6$ to $27 \pm 3 \mu \mathrm{M}$ ) but were significantly sup- pressed, relative to baseline, after antecedent hypoglycemia (35 \pm 2 to $25 \pm 2 \mu \mathrm{M}, P<0.05)$ and antecedent cortisol $(35 \pm 5$ to $25 \pm 3 \mu \mathrm{M}, P<0.05)$. Blood, 3-hydroxybutyrate and plasma nonesterified fatty acid responses fell similarly and significantly in each of the three groups.

\section{Discussion}

The increased incidence of severe hypoglycemia in IDDM patients is the most serious complication of rigorous metabolic control. Recent work has demonstrated that antecedent hypoglycemia can result in reduced neuroendocrine and autonomic nervous system (ANS) responses to subsequent hypoglycemia in normal volunteers (4-7) patients with IDDM (8, 9) or insulinoma (11-13). However, the mechanism(s) responsible for these diminished autonomic counterregulatory responses remain unknown. Based on reports that elevated plasma cortisol levels can diminish subsequent ANS activity to a variety of differing stress (14-18) we have hypothesized that hypoglycemia-associated autonomic failure (1) is caused by antecedent increases of plasma cortisol. To test this hypothesis we have simulated increases in plasma cortisol levels, similar to that occurring during hypoglycemia, but on a background of hyperinsulinemic euglycemia and then examined the ANS response to subsequent hypoglycemia. The results clearly demonstrate that a selective, threefold, physiologic increment in plasma cortisol levels or antecedent hypoglycemia result in similar diminished ANS counterregulatory responses to subsequent hypoglycemia.

Previous studies investigating the effects of antecedent hypoglycemia on subsequent hypoglycemic counterregulation have demonstrated a spectrum of blunted neuroendocrine responses (1-10). Heller et al. (4) and Veneman et al. (7) reported blunted responses of all major neuroendocrine counterregulatory hormones after antecedent hypoglycemia in normal volunteers. Whereas, Davis et al. (5) and Widom et al. (6) observed reductions in some but not all neuroendocrine responses (cortisol [5, 6], epinephrine [6], glucagon [5], growth hormone [5]) during subsequent hypoglycemia in normal humans. Studies involving IDDM patients have provided similar results. Dagogo-Jack et al. (9) reported blunted epinephrine and pancreatic polypeptide counterregulatory responses after antecedent hypoglycemia whereas Davis et al. (8) observed reduced growth hormone and cortisol levels after prior hypoglycemia. Thus it is clear from these studies that antecedent hypoglycemia can result in reduced ANS and neuroendocrine responses during subsequent hypoglycemia. The previous studies, however, were not designed to identify the mechanism(s) responsible for deficient autonomic-neuroendocrine counterregulation after antecedent hypoglycemia. This present study clearly demonstrates that during the final $45 \mathrm{~min}$ of each experiment (steady state period) prior physiologic elevations of plasma cortisol can blunt ANS responses to subsequent hypoglycemia by a similar magnitude to that of antecedent hypoglycemia. Parenthetically, it should be noted that the final 45 min of our experiments was designated steady state based upon the fact that glucose, insulin levels, and glucose infusion rates were stable $(\mathrm{CV}<5.0 \%)$. The term "steady state period" does not indicate that other variables (i.e., neuroendocrine hormones, or MSNA) were also stable during this time.

Antecedent elevations in cortisol had major effects upon the ANS. During the steady state period, plasma epinephrine, 
norepinephrine, pancreatic polypeptide levels, and MSNA were similarly significantly blunted after antecedent cortisol or hypoglycemia compared with control experiments. However, it should be noted that plasma cortisol levels were slightly increased in the antecedent cortisol compared with antecedent hypoglycemia group. Thus it is possible that the stimulus for subsequent ANS suppression was greater in the antecedent cortisol group. Nevertheless, the present results dramatically demonstrate that physiologic increases in plasma cortisol downregulate ANS responses to subsequent hypoglycemia and provides strong support for the argument that increased plasma cortisol can play a major role in antecedent hypoglycemia causing subsequent hypoglycemic autonomic failure. There were differences in the effects of antecedent cortisol or hypoglycemia on initial ANS-neuroendocrine counterregulatory responses. During the first $30 \mathrm{~min}$ of stable hypoglycemia (30-60 min) plasma levels of epinephrine, norepinephrine, and pancreatic polypeptide were greater after prior cortisol compared with antecedent hypoglycemia. This finding needs further investigation but may indicate that antecedent hypoglycemia has a greater effect upon altering the glycemic threshold (i.e., needing a lower plasma glucose) for release of neuroendocrine hormones compared with prior cortisol. Interestingly, there was no difference in the initial response of MSNA after antecedent cortisol or hypoglycemia. We speculate that this may represent an example of differentiation within limbs of the sympathetic nervous system (autonomic adrenomedullary vs peripheral sympathetic neurons).

The mechanism responsible for increases in MSNA during hypoglycemia is not clear. Previous work has documented that decreases in diastolic blood pressure result in large increases in MSNA. Thus as insulin causes vasodilatation and a fall in diastolic blood pressure it may be argued that any observed increases in MSNA during hypoglycemia are due to insulin per se. However, recent work by Hoffman et al. have demonstrated that hyperinsulinemic hypoglycemia results in greater MSNA compared to equivalent levels of insulin in the presence of euglycemia (42). This indicates that, during hypoglycemia, MSNA is reflecting a change in central (i.e., brain) sympathetic drive rather than an adaption to peripheral hemodynamic effects of insulin. The results of this present study confirm this view. In these experiments insulin levels were carefully controlled to be equivalent in all three groups. The fall in diastolic blood pressure was also similar in all groups. Additionally, the increase in heart rate was also equivalent within groups. This is an important point as MSNA is linked to cardiac rhythm. Thus it cannot be argued that observed changes in sympathetic activity were simply due to differences in heart rate during day 2 studies. However, despite equivalent hypoglycemia, insulinemia, heart rate, and diastolic blood pressure, incremental increases in MSNA were dramatically reduced by $\sim 90 \%$ after antecedent cortisol and $\sim 66 \%$ after antecedent hypoglycemia. These data therefore clearly demonstrate that the profound reduction in MSNA after antecedent cortisol or hypoglycemia was due to an alteration in central sympathetic drive rather than a peripheral vasodilatory signal caused by insulin.

The effects of antecedent hypoglycemia on subsequent pituitary neuroendocrine counterregulation have previously been confined to reports of growth hormone responses. In the present study levels of ACTH, $\beta$-endorphin, and growth hormone are reported. This provides a more comprehensive ac- count of the effects of antecedent hypoglycemia on subsequent pituitary hypoglycemic counterregulation. Growth hormone responses were significantly suppressed by antecedent hypoglycemia $(\sim 40 \%)$ but not antecedent cortisol. This degree of suppression of growth hormone response by antecedent hypoglycemia is similar to previous reports $(4,7)$. The fact that antecedent cortisol did not affect growth hormone responses to subsequent hypoglycemia is not surprising. The regulation of growth hormone release does not involve significant ANS input. Therefore, as antecedent increases in cortisol blunt subsequent neuroendocrine counterregulation via effects on the ANS, it may be predicted that growth hormone secretion would not be affected by this mechanism. Interestingly, antecedent hypoglycemia had a much more dramatic effect on suppressing plasma ACTH (about four to fivefold) compared with growth hormone during subsequent hypoglycemia. Parenthetically plasma cortisol levels on day 2 only differed by $\sim 25 \%$ between the three groups and did not reflect the large differences in circulating ACTH levels. This may indicate that the adrenal cortex is more sensitive to circulating levels of ACTH during hypoglycemia or that cortisol secretion in humans saturate in response to only modest elevations of ACTH. Antecedent cortisol had divergent effects on the release of ACTH and $\beta$-endorphin to subsequent hypoglycemia. ACTH responses were suppressed $(\sim 30 \%)$ after antecedent cortisol whereas $\beta$-endorphin responses to hypoglycemia were unaffected. ACTH and $\beta$-endorphin are co-secreted from corticotropes within the anterior pituitary (43). Therefore, it may have been expected that the responses of both peptides would have been similarly blunted by antecedent cortisol. Thus the finding that day 2 ACTH levels were blunted but $\beta$-endorphin responses were unaffected was surprising. However, the present study design does not allow us to identify the putative mechanisms.

Antecedent cortisol had a profound effect on blunting the response of plasma glucagon during day 2 hypoglycemia. We speculate that cortisol produced this effect via reduction of ANS input to the pancreas. The control of glucagon secretion during hypoglycemia is controversial. Evidence exists that glucagon secretion may be controlled by either the sympathetic (44), parasympathetic (45) nervous systems, or by no neural input whatsoever (46). More recent data have demonstrated in conscious dogs, that if brain hypoglycemia is prevented there are no increases in glucagon levels in response to systemic hypoglycemia (47). Taken together the above studies indicate that the brain, via the ANS, and local $\alpha$ cell sensing are important regulators of glucagon release during hypoglycemia. The data from this present study support that concept. The degree of blunting of the glucagon response to day 2 hypoglycemia after antecedent cortisol $(\sim 40 \%)$ was comparable to the diminished epinephrine, norepinephrine, and pancreatic polypeptide responses which were clearly attributable to cortisol's effects on reducing ANS activity. However, antecedent hypoglycemia caused a greater reduction of glucagon response ( $\sim 60 \%$ ) to day 2 hypoglycemia. We interpret this finding to indicate that antecedent hypoglycemia impairs both ANS input into and direct glycemic sensing by the $\alpha$ cell. Whereas antecedent cortisol only impairs ANS input into the pancreas leaving direct glycemic sensing by the $\alpha$ cell intact.

Antecedent hypoglycemia produced a greater blunting of HGP compared to antecedent cortisol. As catecholamine and MSNA responses were similar after antecedent hypoglycemia and cortisol it appears that reduced glucagon levels was the 
mechanism responsible for diminished HGP. In the present study we have not used the labeled glucose infusion method to deliver tritiated glucose (48). Labeling exogenous glucose infusates with a glucose tracer is most valuable during hyperinsulinemic-euglycemic studies where HGP is completely suppressed and large changes in glucose specific activity occur due to greatly increased glucose flux. The conditions during hyperinsulinemic-euglycemic studies are however quite different from hypoglycemic experiments. In the present study, HGP was not completely suppressed and the changes in glucose flux were minimal. During day 2 experiments after antecedent euglycemia no exogenous glucose was required to achieve the desired glycemia. In fact the highest glucose infusion rate used during the entire day 2 studies was only $0.7 \mathrm{mg} / \mathrm{kg}$ per min (during day 2 experiments after antecedent hypoglycemia). Furthermore glucose specific activity was perfectly constant during the final $45 \mathrm{~min}$ of all glucose clamp studies. Therefore, as HGP data were only presented from sections of this study (control period and final $45 \mathrm{~min}$ of glucose clamps) where glucose specific activity was constant, we believe that these data represent reliable estimates of glucose turnover.

Plasma lactate levels during hypoglycemia reflect epinephrine action on muscle glycogenolysis. The finding, therefore, of blunted day 2 plasma lactate levels after antecedent cortisol or hypoglycemia is consistent with reduced plasma epinephrine counterregulatory responses. Along similar lines, blunted day 2 plasma glycerol and alanine levels after antecedent cortisol or hypoglycemia also indicate reduced autonomic adrenomedullary counterregulatory activity at adipose tissue and skeletal muscle, respectively.

Systolic blood pressure (SBP) and heart rate (HR) usually increase during insulin-induced hypoglycemia. This is attributed to increased autonomic adrenomedullary activity. The finding, therefore, that SBP and HR increased similarly in all three groups despite large differences in circulating catecholamines and MSNA was unexpected. We cannot provide a precise mechanism for this finding. However, we speculate that inhibition of negatively chronotropic parasympathetic activity may have offset a similar reduction in positively inotropic and chronotropic sympathetic nervous activity, so that cardiovascular parameters in antecedent hypoglycemia and cortisol protocols remained similar to control studies.

The levels of plasma cortisol obtained in this study are far higher than usual daily morning peaks in normal subjects. Previous studies have demonstrated that peak levels of cortisol in normal males range from $\sim 14$ to $19 \mu \mathrm{g} / \mathrm{dl}(49,50)$. In the present study cortisol levels were elevated to $\sim 30 \mu \mathrm{g} / \mathrm{dl}$ for $2 \mathrm{~h}$ in the late morning and $\sim 25 \mu \mathrm{g} / \mathrm{dl}$ mid afternoon. These levels are therefore greater and occurring later in the day compared with normal morning peaks. Thus it is possible that the timing of the increased plasma cortisol levels may have had an effect in addition to the levels per se. During the last decade there have been considerable advances in the understanding of the effects of glucocorticoids on the brain. There are two specific brain corticosteroid receptors; a type 1 (or MR) and type II (or GR) (51). The type 1 receptors are nearly always fully occupied $(\sim 90 \%)$ even at basal levels of circulating steroids and exert a continuous tonic influence on associated hippocampal hypothalamic function (52). The type II receptor becomes occupied during acute periods of stress and downregulates hypothalamic-autonomic function (53). These receptors explain how circulating levels of corticosterone reduce corticotro- pin-releasing factor (CRF) and ACTH levels in rats (54). Furthermore, these receptors provide a plausible and logical explanation for the effects of cortisol in the present study. We speculate that the increased levels of cortisol activated the type II corticosteroid receptors leading to a reduction in the hypothalamic-autonomic response to subsequent hypoglycemia.

In summary, these studies demonstrate that in normal humans prior elevations of plasma cortisol similar to increases usually occurring during hypoglycemia can result in profound blunting of the hypothalamic-autonomic counterregulatory responses to subsequent hypoglycemia. Prior physiologic elevations in cortisol and antecedent hypoglycemia resulted in similar blunted ANS counterregulatory responses to subsequent hypoglycemia. We conclude that increased plasma cortisol plays a major role in antecedent hypoglycemia causing subsequent hypoglycemic-autonomic counterregulatory failure.

\section{Acknowledgments}

We thank Eric Allen and Pam Venson for technical assistance. We are grateful to Bill Pugh for kindly measuring the pancreatic polypeptide levels reported in the manuscript. We also appreciate the expert secretarial assistance of Carol Haas and the helpful comments of Dr. Michael Pagliassotti in preparing this manuscript.

This work was supported by a grant from the Juvenile Diabetes Foundation International, National Institutes of Health Grants (RO1DK45369), Diabetes Research and Training Center (grant 5P60-AM20593-08), and Clinical Research Center grant (MO1RR00095).

\section{References}

1. Cryer, P.E. 1992. Iatrogenic hypoglycemia as a cause of hypoglycemiaassociated autonomic failure in IDDM. Diabetes. 41:255-260.

2. Gerich, J., M. Langlois, C. Noacco, J. Karam, and P. Forsham. 1993. Lack of a glucagon response to hypoglycemia in diabetes: evidence for an intrinsic pancreatic alpha-cell defect. Science (Wash. DC). 182:171-173.

3. De Feo, P., G. Bolli, G. Perriello, S. De Cosmo, P. Compagnucci, F. Santeusanio, P. Brunetti, J. Gerich, J. Motolese, and P. Brunelti. 1983. The adrenergic contribution to glucose counterregulation in type I diabetes mellitus. Diabetes. 32:887-893.

4. Heller, S., and P.E. Cryer. 1991. Reduced neuroendocrine and symptomatic responses to subsequent hypoglycemia after 1 episode of hypoglycemia in nondiabetic humans. Diabetes. 40:223-226.

5. Davis, M., and H. Shamoon. 1991. Counterregulatory adaption to recurrent hypoglycemia in normal humans. J. Clin. Endocrinol. Metab. 73:995-1001.

6. Widom, B., and D. Simonson. 1992. Intermittent hypoglycemia impairs glucose counterregulation. Diabetes. 41:1597-1602.

7. Veneman, T., A. Mitrakou, M. Mokan, P.E. Cryer, and J. Gerich. 1993. Induction of hypoglycemia unawareness by asymptomatic nocturnal hypoglycemia. Diabetes. 42:1233-1237.

8. Davis, M., M. Mellman, and H. Shamoon. 1992. Further defects in counterregulatory responses induced by recurrent hypoglycemia in IDDM. Diabetes. 41:1335-1340.

9. Dagogo-Jack, S., S. Craft, and P.E. Cryer. 1993. Hypoglycemia-associated autonomic failure in insulin dependent diabetes mellitus. J. Clin. Invest. 91: 819-828.

10. Powell, A., R. Sherwin, and G. Shulman. 1993. Impaired hormonal responses to hypoglycemia in spontaneously diabetic and recurrently hypoglycemic rats. J. Clin. Invest. 92:2667-2674.

11. Davis, M., and H. Shamoon. 1991. Deficient counterregulatory hormone responses during hypoglycemia in a patient with insulinoma. J. Clin. Endocrinol. Metab. 72:788-792.

12. Maran, A., J. Taylor, I. Macdonald, and S. Amiel. 1992. Evidence for reversibility of defective counterregulation in a patient with insulinoma. Diabetic Med. 9:765-768.

13. Mitrakou, A., C. Fanelli, T. Veneman, G. Perriello, S. Calderone, D. Platanisiotis, A. Rambilti, S. Rapts, P. Brunetti, P. Cryer, J. Gerich, and G. Bolli. 1993. Reversibility of unawareness of hypoglycemia in patients in insulinomas. N. Engl. J. Med. 329:834-839.

14. Ramey, E.R., and M. Goldstein. 1957. The adrenal cortex and the sympathetic nervous system. Physiol. Rev. 37:155-195.

15. Roberts-Thomason, I., J.R. Johnsson, P.R. Panhall, W. Taylor, and D.B. 
Frewin. 1991. Differential effect of glucocorticoids on abdominal pain induced by morphine. Pain. 46:133-137.

16. Brown, M.R., and L.A. Fisher. 1986. Glucorticoid suppression of the sympathetic nervous system and adrenal medulla. Life Sci. 39:1003-1012.

17. Kvetnansky, R., K. Fukuhara, K. Pacak, G. Cizza, D. Goldstein, and I.J. Kopin. 1993. Endogenous glucocorticoids restrain catehcholamine synthesis and release at rest and during immobilization stress in rats. Endocrinology. 133: 1411-1419.

18. Komesaroff, P.A., and J.W. Funder. 1994. Differential glucocorticoid effects on catecholamine responses to stress. Am. J. Physiol. 266:E118-E128.

19. Picotti, G.B., M. Carrulra, C. Ravazzani, A.M. Cesura, M. Galva, and M. DaPrada. 1981. Plasma catecholamines in rats exposed to cold: effects of ganglionic and adrenoreceptor blockade. Eur. J. Pharmacol. 69:321-329.

20. Udelsman, R., D.S. Goldstein, D.L. Loriaux, and G.P. Chrousos. 1987. Catecholamine-glucocorticoid interactions during surgical stress. J. Surg. Res. 43:539-545.

21. Tappy, L., D. Randin, P. Vollenweider, L. Vollenweider, N. Pagmot, U. Scherrer, P. Sschneiter, P. Nicod, and E. Jequier. 1994. Mechanisms of dexamethasone-induced insulin resistance in healthy humans. J. Clin. Endocrinol. Metab. 79:1063-1069.

22. Abumrad, N., D. Rabin, M. Diamond, and W. Lacy. 1981. Use of a heated superficial hand vein as an alternative site for measurement of amino acid concentration and for the study of glucose and alanine kinetics in man. Metabolism. 30:936-940.

23. Sherwin, R.S., K. Kramer, J. Robin, and R. Andres. 1978. A model of the kinetics of insulin in man. J. Clin. Invest. 53:1481-1492.

24. De Fronzo, R., J. Tobin, and R. Andres. 1979. Glucose clamp technique: a method for quantifying insulin secretion and resistance. Am. J. Physiol. 273: E216-E223.

25. Wall, J., R. Steele, C. Debodo, and N. Altszuler. 1957. Effect of insulin on utilization and production of circiulating glucose. Am. J. Physiol. 189:43-50.

26. Wallin, B., G. Sundiot, B. Eriksson, P. Domniak, H. Grobecker, and L. Lindblad. 1981. Plasma noradrenaline correlates by sympathetic muscle nerve activity in normotensive man. Acta Physiol. Scand. 111:69-73.

27. Fagius, J., F. Niklasson, and C. Beme. 1986. Sympathetic outflow in human muscle nerves increases during hypoglycemia. Diabetes. 35:1126-1129.

28. Fagius, J., and C. Beme. 1989. Changes of sympathetic nerve activity induced by 2-deoxy-D-glucose infusion in humans. Am. J. Physiol. 256:E714E720.

29. Anderson, E., P. Hoffman, T. Balon, K. Sinkey, and A. Mark. 1992. Hyperinsulinemia produces both sympathetic neural activation and vasodilatation in normal humans. J. Clin. Invest. 87:2246-2252.

30. Wallin, B., and J. Fagius. 1988. Peripheral sympathetic neural activation in conscious humans. Ann Rev. Physiol. 50:565-576.

31. Goldstein, D., R. Bonner, R. Zimlichman, T. Zahn, R. Cannon, O. Rosing, R. Stull, and H. Keiser. 1986. Indices of sympathetic vascular innervation in sympathectomized patients. J. Autonomic Nerv. Syst. 15:309-315.

32. Gans, R., M. Bilo, W. Maarschollierweed, R. Heine, J. Nauta, and A. Donker. 1991. Exogenous insulin augments in healthy volunteers the cardiovascular reactivity to noradrenaline but not to angiotensin II. J. Clin. Invest. 88: $512-518$

33. Cherrington, A.D., W. Lacy, and J.L. Chiasson. 1978. Effect of glucagon on glucose production during insulin deficiency in the dog. J. Clin. Invest. 62: 664-667.

34. Aguilar-Parada, E., A.M. Eisentraut, and R.H. Unger. 1969. Pancreatic glucagon secretion in normal and diabetic subjects. Am. J. Med. Sci. 257:415419 .

35. Wide, L., and J. Porath. 1966. Radioimmunoassay of proteins with the uses of sephadex-coupled antibodies. Biochim. Biophys. Acta. 130:257-260.
36. Causon, R., M. Caruthers, and R. Rodnight. 1982. Assay of plasma catecholamines by liquid chromatography with electrochemical detection. Anal. Biochem. 116:223-226.

37. Hunter, W., and F. Greenwood. 1962. Preparation of $\left[{ }^{131} \mathrm{I}\right]$-labeled human growth hormone of high specific activity. Nature (Lond.). 194:495-496.

38. Hagopian, W., E. Lever, D. Cen, D. Emmonoud, K. Polonsky, W. Pugh, A. Moosa, and J. Jaspan. 1983. Predominance of renal and absence of hepatic metabolism of pancreatic polypeptide in the dog. Am. J. Physiol. 245:171-177.

39. Nicholson, W., S. DeCherney, R. Jackson, and D.N. Orth. 1987. Pituitary and hypothalamic hormones in normal and neoplastic adrenal medullae: biologically active corticotropin-releasing hormone and corticotropin. Regu. Pept. 18:173-188.

40. Lloyd, B., J. Barrin, P. Smythe, and K.G.M.M. Alberti. 1978. Enzymatic fluorometric continuous flow assays for blood glucose, lactate, pyruvate, alanine, glycerol and 3-hydroxybutyrate. Clin. Chem. 24:1724-1729.

41. Ho, R.J. 1970 . Radiochemical assay of long chain fatty acids using ${ }^{63} \mathrm{Nl}$ as tracer. Anal. Biochem. 26:105-113.

42. Hoffman, R., C. Sinkey, and E.A. Anderson. 1994. Hypoglycemia increases muscle sympathetic nerve activity in IDDM and control subjects. Diabetes Care. 17:673-680.

43. Guillemin, R., T. Vargo, J. Rossier, S. Minick, N. Ling, and C. Rivier. 1977. $\beta$-endorphin and adrenal corticotropin are secreted concomitantly by the pituitary gland. Science (Wash. DC). 197:1367-1369.

44. Gerich, J.E., M. Langlois, C. Noacco, V. Schneider, and P.H. Forsham. 1974. Adrenergic modulation of pancreatic glucagon secretion in man. J. Clin. Invest. 53:1441-1446.

45. Bloom, S.R., N. Vaughan, and R. Russell. 1974. Vagal control of glucagon release in man. Lancet. ii:546-549.

46. Palmer, J., D. Henry, J. Benson, D. Johnson, and J.W. Ensinck. 1976. Glucagon response to hypoglycemia in sympathetomized man. J. Clin. Invest. 57:522-525.

47. Biggers, D., S. Myers, D. Neal, R. Stinson, N. Cooper, J. Jaspan, P. Williams, A. Cherrington, and R.T. Frizzell. 1989. Role of brain in counterregulation of insulin induced hypoglycemia in dogs. Diabetes. 38:7-16.

48. Finegood, D., R. Bergman, and M. Vranic. 1987. Estimation of endogenous glucose production during hyperinsulinemic euglycemic clamps: comparison of unlabeled and labeled exogenous glucose infusates. Diabetes. 36:914924

49. Horrocks, P., A. Jones, W. Ratcliffe, G. Holder, A. White, R. Holder, J. Ratcliffe, and D.R. London. 1990. Patterns of ACTH and cortisol pulsatility over twenty-four hours in normal males and females. Clin. Endocrinol. 32:127134

50. Kerrigan, J., J. Veldhuis, S. Leyo, A. Iranmanesh, and A.D. Rogol. 1993. Estimation of daily cortisol production and clearance rates in normal pubertal male by deconvolution analysis. J. Clin. Endocrinol. Metab. 76:1505-1510.

51. De Kloet, E., G. Wallach, and B. McEwan. 1975. Differences in corticosterone and dexamethasone binding to rat brain and pituitary. Endocrinology. 96:598-609.

52. De Kloet, E., and J. Reul. 1987. Feedback action and tonic influences of corticosteroids on brain functions: a concept arising from the heterogeneity of brain receptor systems. Psychoneuroendocrinology 12:83-105.

53. De Kloet, E., A. Ratka, J. Reul, W. Sutanto, and J. van Eckelen. 1987. Corticosteroid receptor types in brain regulation and putative function. Ann. NY Acad. Sci. 512:351-361.

54. Bradbury, M., S. Akana, C. Cascio, N. Levin, L. Jacobson, and M. Dallman. 1991. Regulation of basal ACTH secretion by corticosterone is mediated by both type I (MR) and type II (GR) receptors in rat brain. J. Steroid Biochem. Mol. Biol. 40:133-142. 